\title{
Research Letter \\ Properties of Reinforced Concrete Steel Rebars Exposed to High Temperatures
}

\author{
Illker Bekir Topçu and Cenk Karakurt \\ Department of Civil Engineering, Eskişehir Osmangazi University, 26480 Eskişehir, Turkey \\ Correspondence should be addressed to Cenk Karakurt, ckarakurt@ogu.edu.tr
}

Received 12 February 2008; Accepted 31 March 2008

Recommended by Rajiv S. Mishra

\begin{abstract}
The deterioration of the mechanical properties of yield strength and modulus of elasticity is considered as the primary element affecting the performance of steel structures under fire. In this study, hot-rolled S220 and S420 reinforcement steel rebars were subjected to high temperatures to investigate the fire performance of these materials. It is aimed to determine the remaining mechanical properties of steel rebars after elevated temperatures. Steels were subjected to $20,100,200,300,500,800$, and $950^{\circ} \mathrm{C}$ temperatures for 3 hours and tensile tests were carried out. Effect of temperature on mechanical behavior of S220 and S420 were determined. All mechanical properties were reduced due to the temperature increase of the steel rebars. It is seen that mechanical properties of S420 steel was influenced more than S220 steel at elevated temperatures.
\end{abstract}

Copyright ( $) 2008$ İlker B. Topçu and C. Karakurt. This is an open access article distributed under the Creative Commons Attribution License, which permits unrestricted use, distribution, and reproduction in any medium, provided the original work is properly cited.

\section{INTRODUCTION}

Fire remains one of the serious potential risks to most buildings and structures. Since concrete is widely used in construction, research on fire resistance of concrete becomes more and more important. Many researchers all over the world have done some researches on this subject. The mechanical properties of all common building materials decrease with elevation of temperature. The behavior of a reinforced concrete structure in fire conditions is governed by the properties of the constituent materials, concrete, and steel, at high temperature. Both concrete and steel undergo considerable change in their strength, physical properties, and stiffness by the effects of heating, and some of these changes are not recoverable after subsequent cooling [1].

It is necessary to have safe, economical, and easily applicable design methods for steel members subjected to fire. However, without fire protection, steel structures may suffer serious damage or even collapse in a fire catastrophe. This is because the mechanical properties of steel deteriorate by heat during fires, and the yield strength of conventional steel at $600^{\circ} \mathrm{C}$ is less than $1 / 3$ of the specified yield strength at room temperature [2]. Therefore, conventional steels normally require fire-resistant coating to be applied [3].
The temperature increase in the steel member is governed by the principles of heat transfer. Consequently, it must be recognized that the temperature of the steel member(s) will not usually be the same as the fire temperature in a compartment or in the exterior flame plume.Protected steel will experience a much slower temperature rise during a fire exposure than unprotected steel. Also, fire effect on steel member is influenced with its distance from the center of the fire, and if more ventilation occurs near the steel in a fuelcontrolled condition, wherein the ventilation helps to cool the steel by dissipating heat to the surrounding environment [4].

Especially, temperature increase of steel and concrete in composite steel-concrete elements leads to a decrease of mechanical properties such as yield stress, Young's modulus, and ultimate compressive strength of concrete [5]. Thus, load bearing of steel decreases when steel or composite structure is subjected to a fire action. If the duration and the intensity of the fire are large enough, the load bearing resistance can fall to the level of the applied load resulting in the collapse of the structure. However, the failure of the World Trade Centre on 11th September 2001 and, in particular, of building WTC7 alerted the engineering profession to the possibility of connection failure under fire conditions [6]. In 
this study, S220 and S420 ribbed concrete steel rebars were subjected to 7 different temperatures to determine the high temperature behavior of reinforcement steels.

\section{EXPERIMENTAL STUDY}

Experimental studies were conducted with 10 and $16 \mathrm{~mm}$ in diameter and $200 \mathrm{~mm}$ in length S220 and S420 reinforcement steel rebars. Test specimens were subjected to 20, 100, 200, $300,500,800$, and $950^{\circ} \mathrm{C}$ temperatures in a high furnace for 3 hours, respectively. At the end of the curing process, steels were cooled naturally to the room temperature. Subsequently, tensile tests were applied to steel reinforcement rebars. According to EN 10002-1 tensile strength, yield strength and elongation of the steel rebars were determined for elevated temperatures [7]. The steel specimens tensile strength tests were performed with 60 tons of loading capacity universal tensile strength test machine. The loading speed of the test machine is adjusted according to TS 708 code [8].

\section{TEST RESULTS AND EVALUATIONS}

\subsection{Stress-strain relations}

The average values for stress-strain relationship for specimens that were exposed to various temperatures are given in Figures 1 and 2. The curves in Figures 1 and 2 were drawn with the average test results of 10 and $16 \mathrm{~mm}$ in diameter steel specimens. The test conditions were meant to simulate a building that had a fire so the changes in the mechanical properties of reinforcing steels used in structures exposed to high temperature could be determined. As seen from Figure 1, temperatures below $500^{\circ} \mathrm{C}$ have no significant effect on mechanical properties of preheated and cooled S220 steel rebars. The yield strength and splitting tensile strengths of S220 steels were similar up to this temperature. However, the yield strength and splitting tensile strength of the S220 steel rebars are reducing with the increase of temperatures over $800^{\circ} \mathrm{C}$. A similar behavior can be seen from the test results of S420-ribbed steel rebars (Figure 2). All high temperature subjected steel specimens became more ductile temperatures above $800^{\circ} \mathrm{C}$.

\subsection{Yield strength}

Yield strength of both reinforcing steel rebars was affected with the elevated exposure temperatures. It can be concluded from Figure 3 that there is no variation in yield strength of reinforcing steels with cover up to $300^{\circ} \mathrm{C}$. Plain reinforcing steel rebars have experienced the strain hardening already for this temperature. According to Eurocode and TS EN 1993 , before $400^{\circ} \mathrm{C}$ there is no decrease in yield strength, but after this temperature a significant yield strength loss occurs [9]. The yield strength losses of both S220 and S420 steel rebars were $46 \%$ and $84 \%$ for $800^{\circ} \mathrm{C}$ exposure temperature, respectively. For further increase of temperature at $950^{\circ} \mathrm{C}$, yield strength decreases were $64 \%$ and $89 \%$, respectively. According to these results, the remaining yield strength of

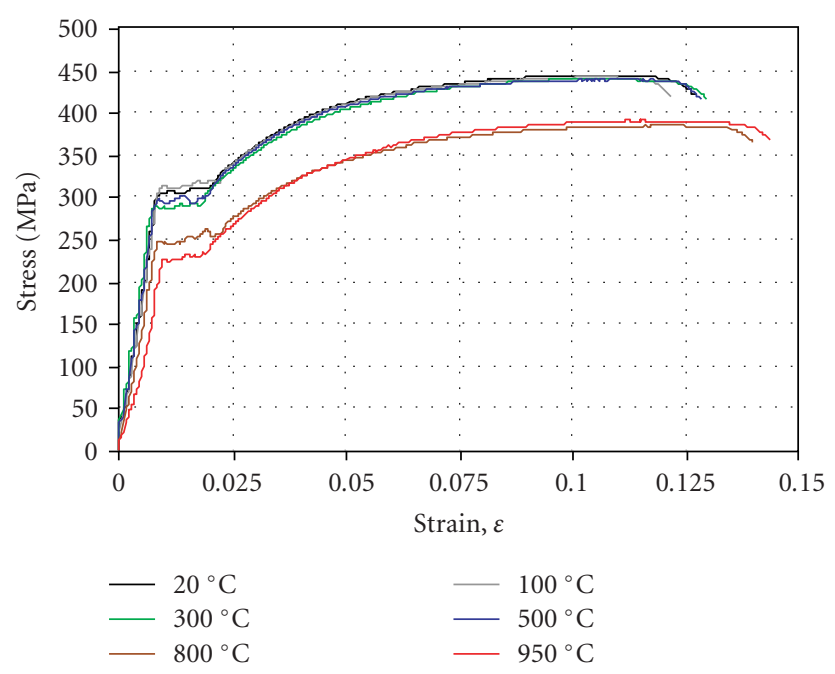

FIgURE 1: Stress-strain curve of S220 steel rebar.

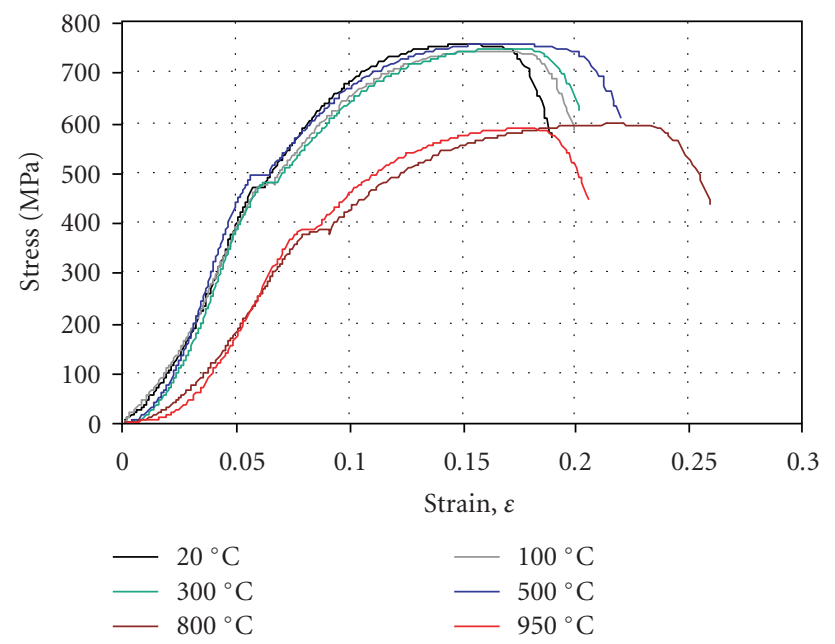

FIGURE 2: Stress-strain curve of S420-ribbed steel rebar.

S220 steel reinforcing rebar is higher than S420-ribbed steel rebar after high-temperature exposure.

\subsection{Tensile strength}

The tensile strength variation of steel reinforcement rebars exposed to elevated temperatures is given in Figure 4. On the light of these results, there was no significance reducing of tensile strength for both types of steel rebars up to $500^{\circ} \mathrm{C}$ temperature. The tensile strength losses of both S220 and S420 steel rebars were $51 \%$ and $85 \%$ for $800^{\circ} \mathrm{C}$ exposure temperature, respectively. For the highest exposure temperature at $950^{\circ} \mathrm{C}$, tensile strength decreases were $60 \%$ and $90 \%$, respectively. According to these results, the remaining tensile strength of S220 steel reinforcing rebar is higher than S420ribbed steel rebar after high-temperature exposure. However, it should be considered that the possibility of complete strength loss of steel rebars at high temperatures when a structure is subjected to a huge fire. The remaining strengths of both reinforcing steel rebars after $500^{\circ} \mathrm{C}$ are lower than the 


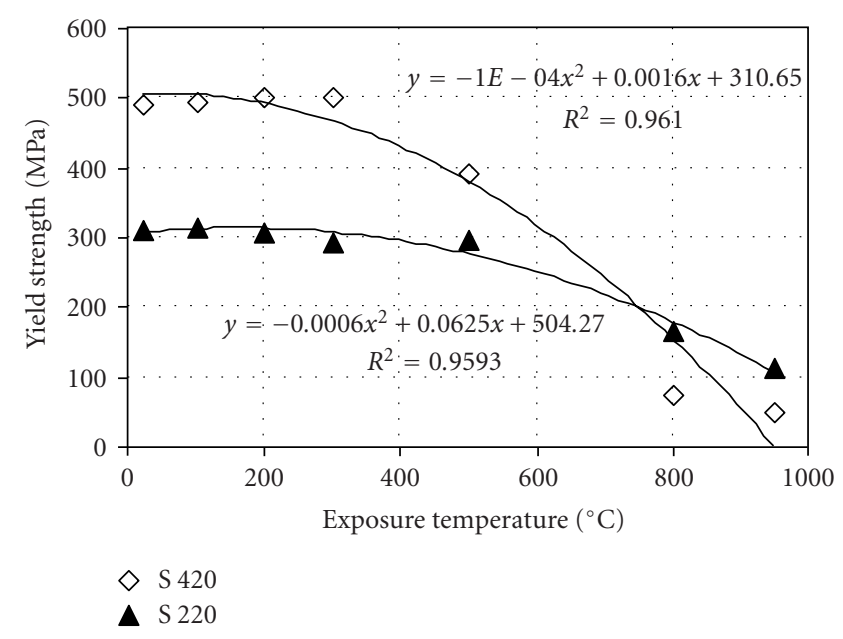

FIGURE 3: Yield strength of steel rebars against temperature.

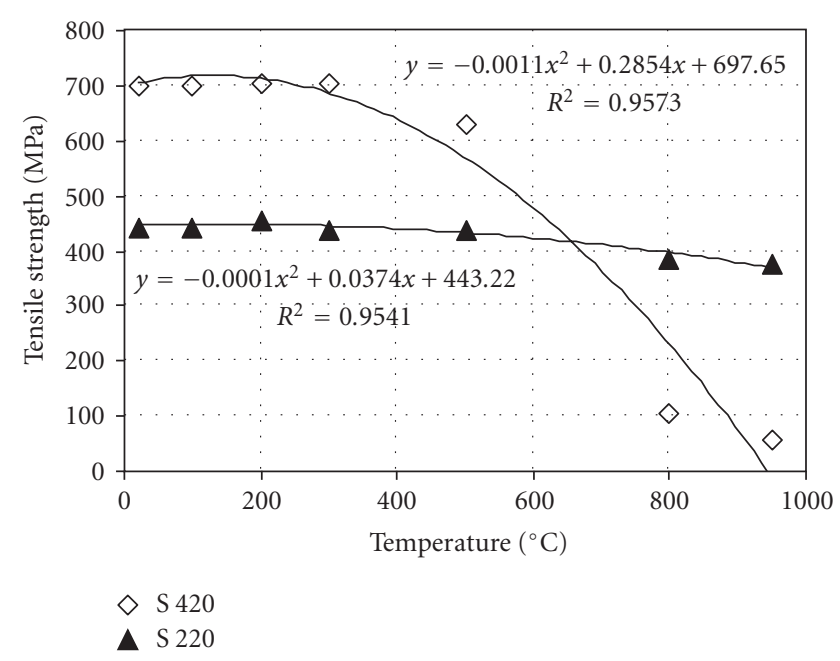

FIgURE 4: Tensile strength of steel rebars against temperature.

design strengths of these steels. Consequently, the remaining strength of the steel rebars in structures is influenced with the exposure time and type of fire depending on the heat transfer through concrete cover to steel parts [10].

\subsection{Elongation}

The relation between high temperature and splitting elongation ratio can be seen from Figure 5. The figure is demonstrated that both steel rebars show a same elongation behavior under elevated temperatures. The elongation ratios of S220 steel rebars are higher than S420 rebars depending on the ductile fracture behavior of this steel. After a fire inside the reinforced concrete building, the deflections of the structural members increase with the ductile behavior of the steel reinforcement at high temperatures.

The elongation ratios were slightly increased up to $300^{\circ} \mathrm{C}$, however, above this temperature material becomes brittle with decrease of the elongation values. The elongation losses of both S220 and S420 steel rebars were 1.2\% and 1.6\%

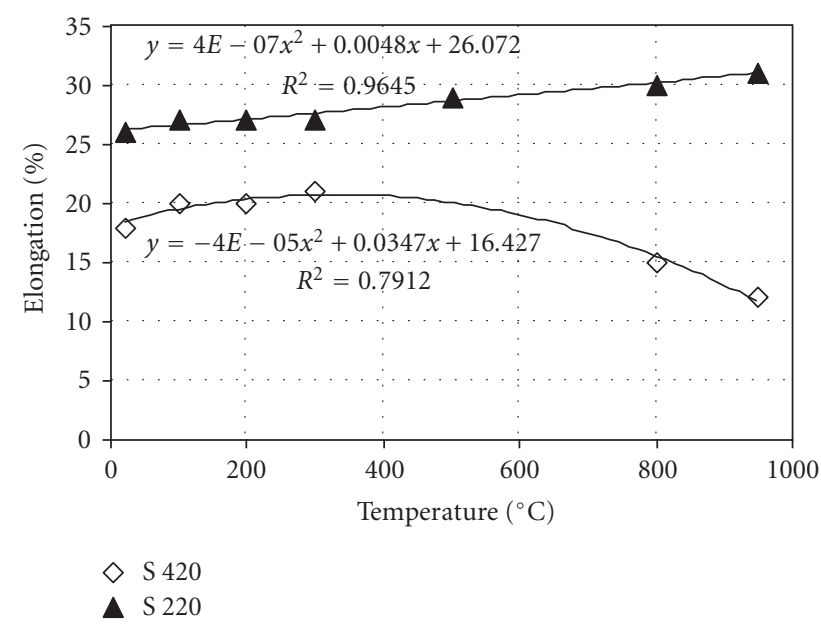

FIGURE 5: Elongation ratios of steel rebars against temperature.

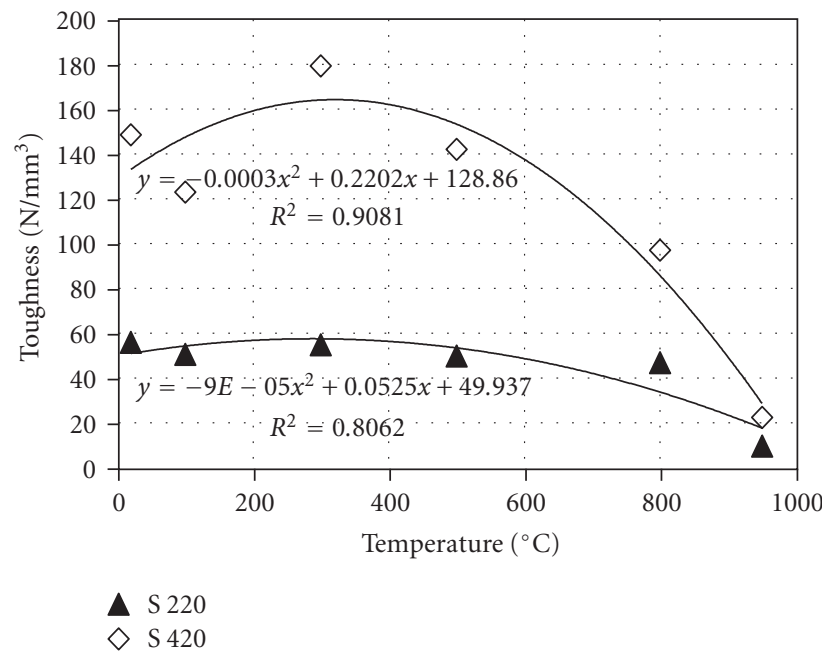

FiguRE 6: Toughness of steel rebars against temperature.

for $800^{\circ} \mathrm{C}$ exposure temperature, respectively. For further increase of temperature at $950^{\circ} \mathrm{C}$, elongation ratios decreases were $1.6 \%$ and $3.3 \%$, respectively. According to these results, the elongation capacity of S420 steel is lower than S220 steel under elevated temperatures. The S420 steel showed a brittle fracture behavior under elevated temperatures. This behavior is not sufficient for rebar steel in reinforced concrete structures.

\subsection{Toughness}

The energy absorbent capacity of materials used in construction should be higher against dynamic earthquake loads. The fracture energy of materials is defined with the toughness concept. The toughness values of the steel rebars used in experimental studies are given in Figure 6. According to test results, the toughness values of both types of steels were decreased after elevated temperature exposure. However, up to $300^{\circ} \mathrm{C}$, the toughness values were increased due to the ductile behavior of both steels. The toughness losses of both 
S220 and S420 steel rebars were $16 \%$ and $35 \%$ for $800^{\circ} \mathrm{C}$ exposure temperature, respectively. For further increase of temperature at $950^{\circ} \mathrm{C}$, toughness decreases were $82 \%$ and $88 \%$, respectively.

\section{CONCLUSIONS}

As described in the previous studies, steel structural members loose strength under elevated temperatures. In this study, the mechanical properties of steel rebars were investigated which exposed to high temperatures and cooled to room temperature. According to test results, the most common reinforcing steel rebar S420 showed a brittle fracture mechanism under elevated temperatures. Splitting yield strength, tensile strength, elongation, and toughness values were low for S220 steel. These results demonstrate that S220 type of steel rebar is less affected than S420 steel under elevated temperatures. The authors suggest that the protective cover thickness should be higher for increasing the fire safety of reinforced concrete members.

\section{REFERENCES}

[1] B. Chen and J. Liu, "Residual strength of hybrid-fiberreinforced high-strength concrete after exposure to high temperatures," Cement and Concrete Research, vol. 34, no. 6, pp. 1065-1069, 2004.

[2] E. Ünlüoğlu, İ. B. Topçu, and B. Yalaman, "Concrete cover effect on reinforced concrete bars exposed to high temperatures," Construction and Building Materials, vol. 21, no. 6, pp. 1155-1160, 2007.

[3] C.-S. Poon, S. Azhar, M. Anson, and Y.-L. Wong, "Strength and durability recovery of fire-damaged concrete after postfire-curing," Cement and Concrete Research, vol. 31, no. 9, pp. 1307-1318, 2001.

[4] R. G. Gewain, N. R. Iwankiw, and F. Alfawakhiri, Facts for Steel Buildings, American Institute of Steel Construction, Chicago, Ill, USA, 2003.

[5] J. Ding, G.-Q. Li, and Y. Sakumoto, "Parametric studies on fire resistance of fire-resistant steel members," Journal of Constructional Steel Research, vol. 60, no. 7, pp. 1007-1027, 2004.

[6] F. Wald, L. S. da Silva, D. B. Moore, et al., "Experimental behaviour of a steel structure under natural fire," Fire Safety Journal, vol. 41, no. 7, pp. 509-522, 2006.

[7] TS 138 EN 10002-1, "Metallic materials-tensile testing-part 1: method of test at ambient temperature," Turkish Standards Institution, Ankara, Turkey, 2004.

[8] TS 708, "Steel rebars for concrete," Turkish Standards Institution, Ankara, Turkey, 1996.

[9] TS 138 EN 1993, "Design of steel structures—part 1-2: general rules-structural fire design,” Turkish Standards Institution, Ankara, Turkey, 2005.

[10] İ. B. Topçu and B. Işııdağ, "The effect of cover thickness on rebars exposed to elevated temperatures," Construction and Building Materials. In press. 

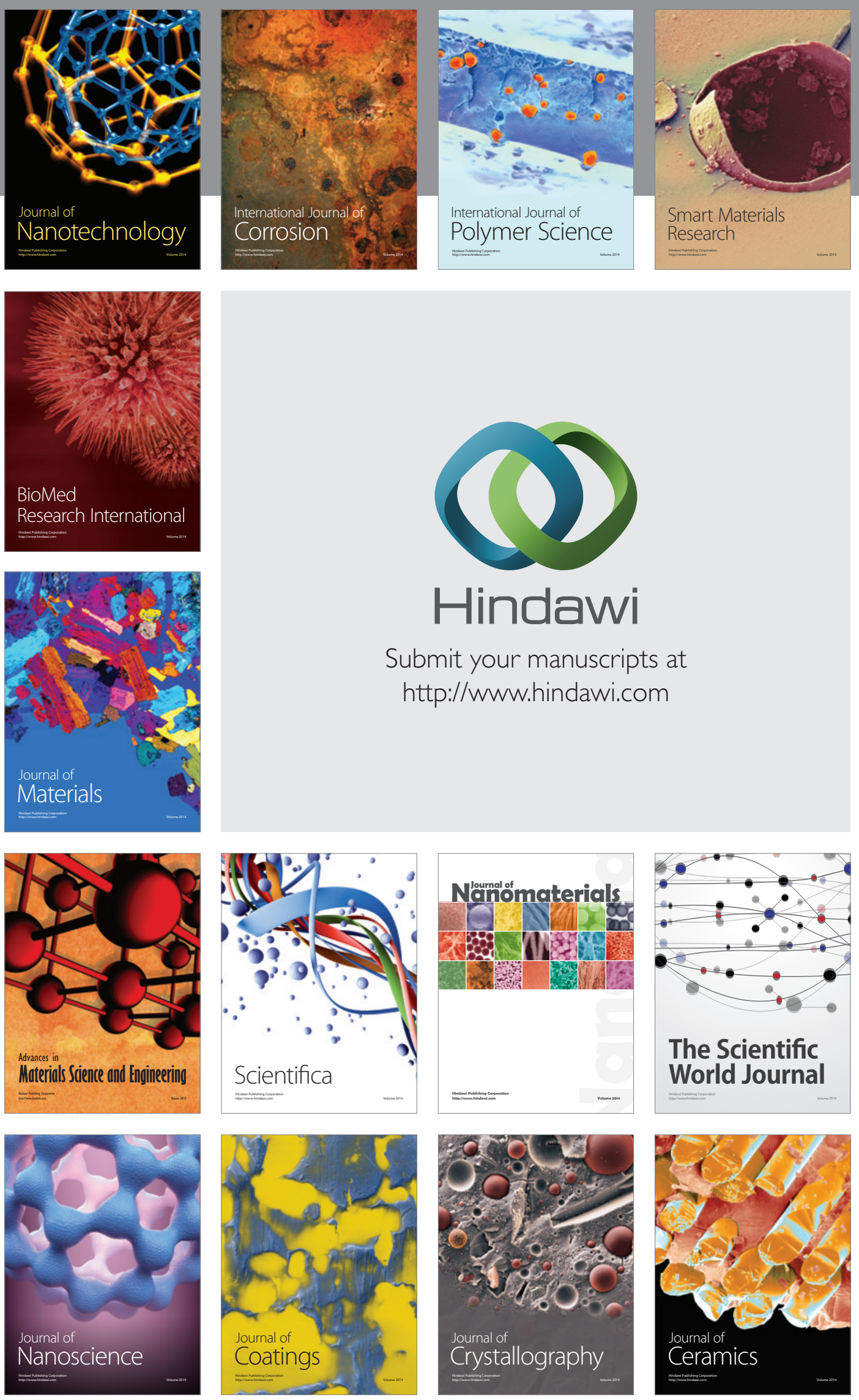

The Scientific World Journal

Submit your manuscripts at

http://www.hindawi.com

\section{World Journal}

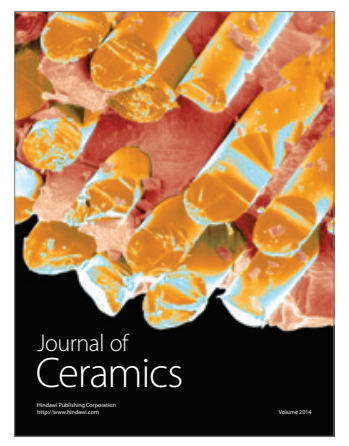

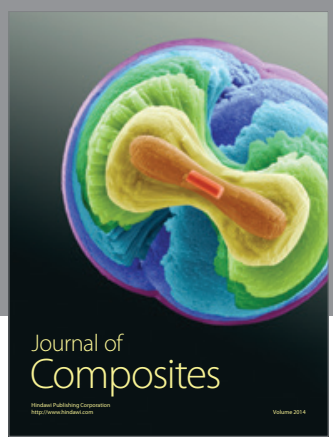
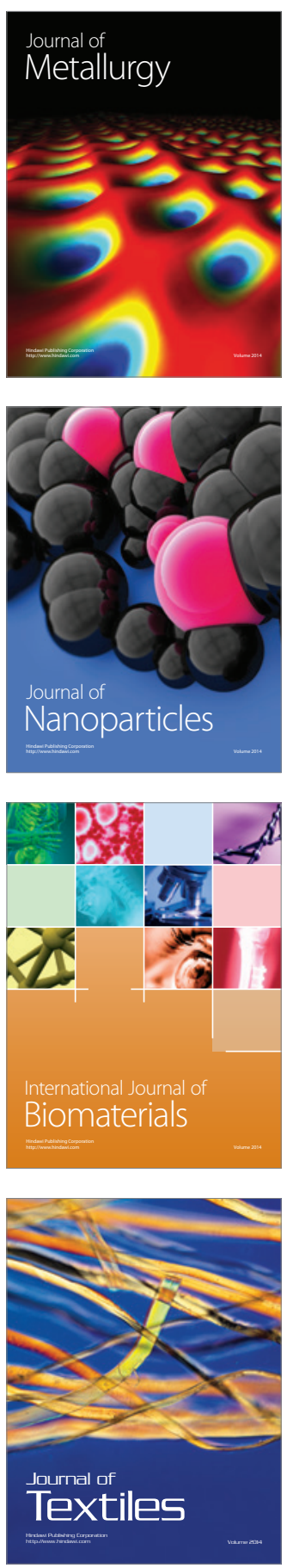